\title{
Methane Clathrate Formation is Catalyzed and Kinetically Inhibited by a Same Molecule: Two Facets of Methanol
}

Zhaoqian $\mathrm{Su}^{1}$, Saman Alavi ${ }^{2}$, John Ripmeester ${ }^{3}$, Gedaliah Wolosh ${ }^{4}$, Cristiano L. Dias ${ }^{5 *}$

${ }^{1}$ Albert Einstein College of Medicine, Department of Systems and Computational Biology, Bronx, 10461, New York

${ }^{2}$ University of Ottawa, Department of Chemistry and Biomolecular Sciences, Ottawa, Ontario, K1N 6N5, Canada

${ }^{3}$ National Research Council of Canada, 100 Sussex Dr., Ottawa, Ontario, K1A 0R6, Canada

${ }^{4}$ New Jersey Institute of Technology, Academic and Research Computing Systems, University Heights, Newark, 07102 , New Jersey

${ }^{5}$ New Jersey Institute of Technology, Department of Physics, University Heights, Newark, 07102, New Jersey

Email: cld@njit.edu

\section{Content}

1) Force field for methane and methanol

Figure $\mathbf{S 1}$

2) Details of simulation setup S3

Table S1

Table S2

3) Methane-methanol interactions S4-S5

Figure S2

Figure S3

4) Cage packing in the presence of methanol S6-S7

Figure S4

Figure S5 


\section{1-Force field for methane and methanol}
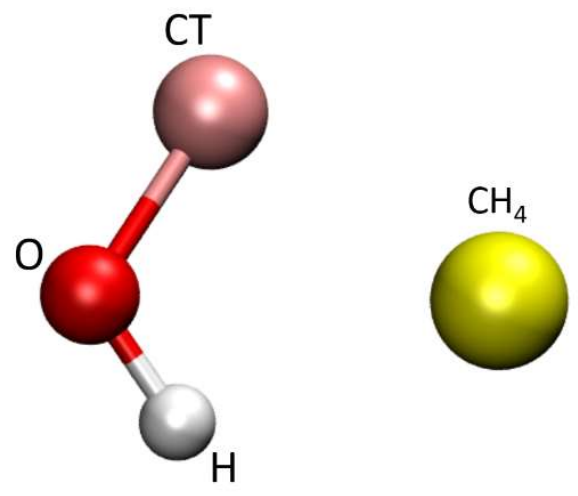

\begin{tabular}{|l|l|l|l|}
\hline \multicolumn{1}{|c|}{ Atom } & $\mathrm{q}[\mathrm{e}]$ & $\sigma[\mathrm{nm}]$ & $\varepsilon[\mathrm{kJ} / \mathrm{mol}]$ \\
\hline $\mathrm{CT}$ & +0.265 & 0.374 & 0.875 \\
\hline $\mathrm{O}$ & -0.700 & 0.303 & 0.719 \\
\hline $\mathrm{H}$ & +0.435 & - & - \\
\hline $\mathrm{CH}_{4}$ & - & 0.373 & 1.2305 \\
\hline
\end{tabular}

Figure S1-Force field parameters for methane $\left(\mathrm{CH}_{4}\right)$ [1] and methanol $\left(\mathrm{CH}_{3} \mathrm{OH}\right)$ [2] where $\mathrm{CT}$ stands for a united atom corresponding to the $\mathrm{CH}_{3}$ group. 


\section{2-Details of the simulation setup}

\begin{tabular}{|c|c|c|c|c|}
\hline Temperature (K) & $\mathbf{x}_{\mathbf{o l}}$ & Water & Methanol & Time $(\boldsymbol{\mu s})$ \\
\hline \multirow{2}{*}{$\mathbf{2 3 0}$} & 0 & 3,335 & 0 & $6 \times 5$ \\
\cline { 2 - 5 } & 0.04 & 3,191 & 144 & $7 \times 2$ \\
\hline \multirow{2}{*}{$\mathbf{2 5 0}$} & 0 & 3,335 & 0 & $7 \times 1.5$ \\
\cline { 2 - 5 } & 0.04 & 3,191 & 144 & $6 \times 1.5$ \\
\cline { 2 - 5 } & 0 & 3,335 & 0 & $13 \times 1$ \\
\hline
\end{tabular}

Table S1-Details of the boxes used in our simulations. All simulations contain 200 methane molecules and they are performed at $50 \mathrm{MPa}$. The number of water and methanol molecules were adjusted to account for a methane mole fraction of 0.056 and the methanol mole fraction $\mathrm{x}_{\mathrm{ol}}$ given in the table. The length and number of trajectories is given in the last column.

\begin{tabular}{|c|c|c|c|}
\hline System & $\begin{array}{c}\text { Temp. } \\
(\mathrm{K})\end{array}$ & $\begin{array}{c}\text { Number of simulations X } \\
\text { Umbrella sampling windows X } \\
\text { Time per window }\end{array}$ & Water/Methane/Methanol \\
\hline Water + Methane & 270 & $1 \times 25 \times 200 \mathrm{~ns}$ & $2000 / 2 / 0$ \\
\hline $\begin{array}{c}\text { Water + Methane } \\
+\mathrm{x}_{\mathrm{ol}}=0.075\end{array}$ & 270 & $1 \times 25 \times 200 \mathrm{~ns}$ & $2000 / 2 / 164$ \\
\hline $\begin{array}{c}\text { Water + Methane } \\
+\mathrm{x}_{\mathrm{ol}}=0.14\end{array}$ & 270 & $1 \times 25 \times 200 \mathrm{~ns}$ & $2000 / 2 / 328$ \\
\hline $\begin{array}{c}\text { Water + Methane } \\
+\quad x_{\mathrm{ol}}=0.075\end{array}$ & 250 & $1 \times 25 \times 200 \mathrm{~ns}$ & $2000 / 2 / 164$ \\
\hline $\begin{array}{c}\text { Water + Methane } \\
+\mathrm{x}_{\mathrm{ol}}=0.14\end{array}$ & 250 & $2 \times 25 \times 200 \mathrm{~ns}$ & $2000 / 2 / 328$ \\
\hline
\end{tabular}

Table S2-Details of umbrella sampling simulations. All simulations contain 2 methane molecules and they are performed at $50 \mathrm{MPa}$. 


\section{3-Methane-methanol interactions}

- $\quad$ Fig. S2 shows the methanol-methane radial distribution function (RDF) computed at different temperature for the methane-dimer simulations at $\xi=1.50 \mathrm{~nm}$.

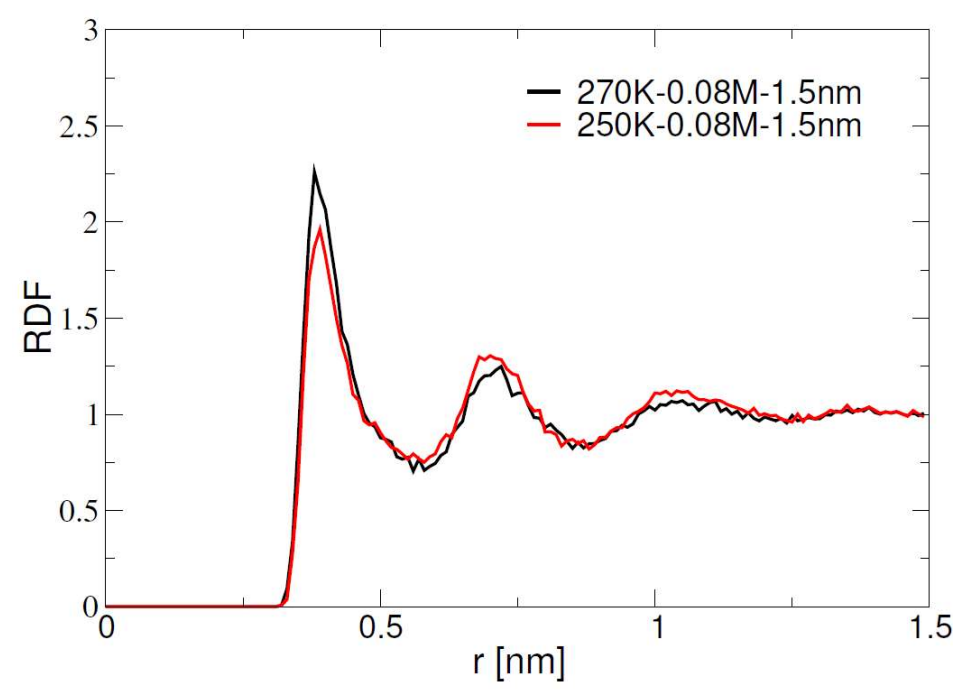

Figure S2- Radial distribution functions of methanol and methane molecules in $0.075 \mathrm{M}$ methanol solutions at $250 \mathrm{~K}$ and $270 \mathrm{~K}$. These functions are computed when methane molecules are far apart, i.e., at $\xi=1.50 \mathrm{~nm}$.

- The methane-methanol potential of mean force (PMF) is computed from the RDF using:

$$
\operatorname{PMF}(\xi)=-k_{b} T \ln (\mathrm{RDF}(\xi))
$$

- The PMF is decomposed into entropic $(\Delta S)$ and enthalpic $(\Delta H)$ contributions as follow:

$$
\Delta S(\xi)=-\left(\frac{\partial P M F(\xi)}{\partial T}\right)=-\frac{P M F_{270 K}(\xi)-P M F_{250 K}(\xi)}{\Delta T}
$$

and

$$
\Delta H(\xi)=\operatorname{PMF}(\xi)+\mathrm{T} \Delta \mathrm{S}(\xi)
$$


- The PMF computed at $\mathrm{T}=250 \mathrm{~K}$ is shown in black in Fig. S3 as well as $\Delta H$ (in red) and $-T \Delta S$ (in blue). This figure shows that at short $\xi$ distance, methane-methanol interactions are dominated by entropy, which is a characteristic property of hydrophobic interactions.

Figure S3-PMF of methane-methanol interaction decomposed into enthalpy (red) and entropy (blue) components for simulations performed in $0.075 \mathrm{M}$ methanol solutions at $250 \mathrm{~K}$.

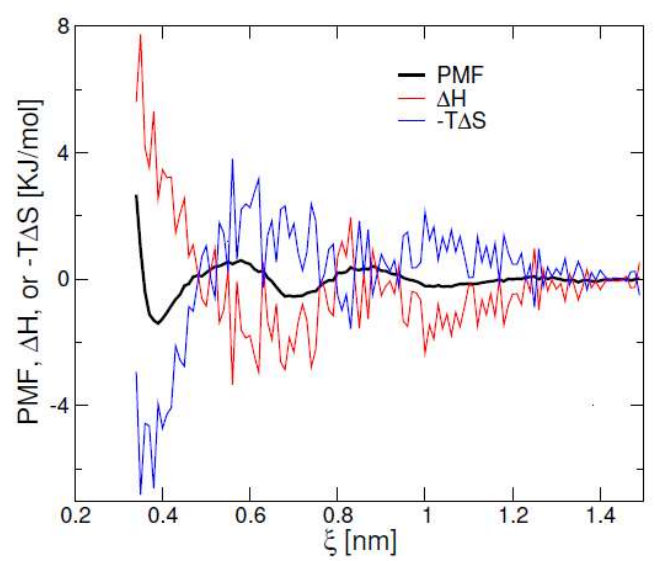




\section{4-Cage packing in the presence of methanol}
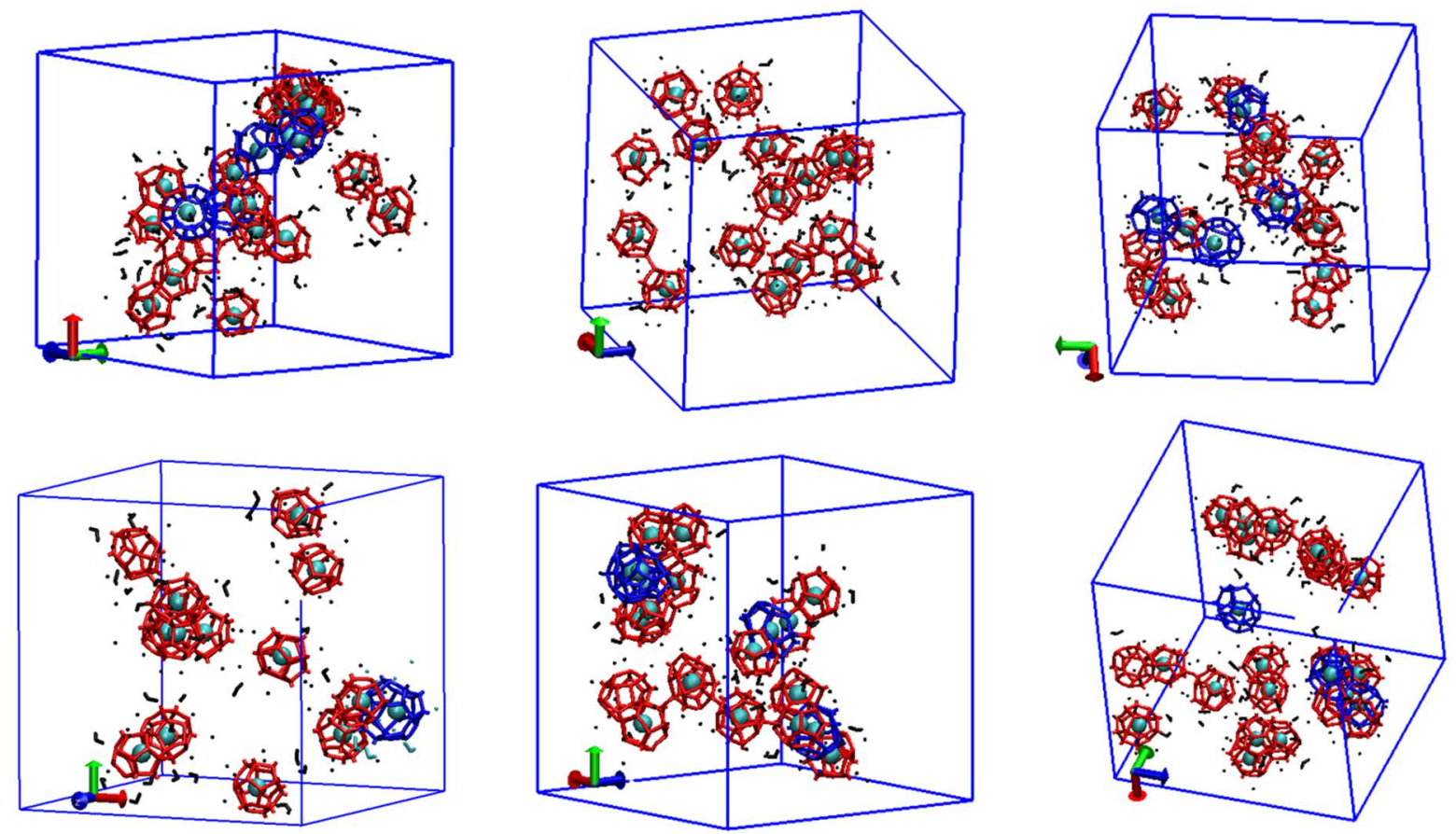

Figure S4-Characteristic configurations of methane clathrates in the presence of 0.04 mole fraction of methanol at $230 \mathrm{~K}$. In these panels, methane molecules inside cages are shown using a van der Waals representation in cyan whereas $5^{12}$, $5^{12} 6^{2}$, and $5^{12} 6^{4}$ cages are represented in red, blue, and green, respectively. Methane and methanol molecules within $0.5 \mathrm{~nm}$ from cages are shown in licorice representation in black. 

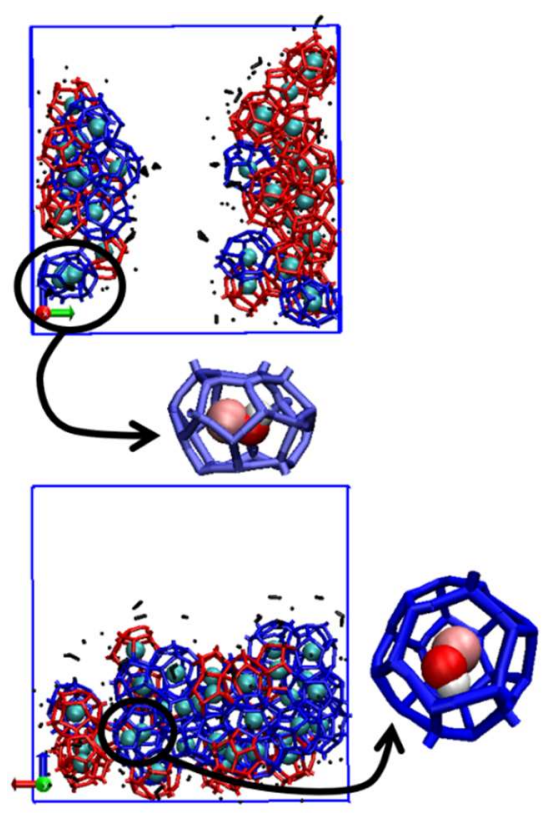
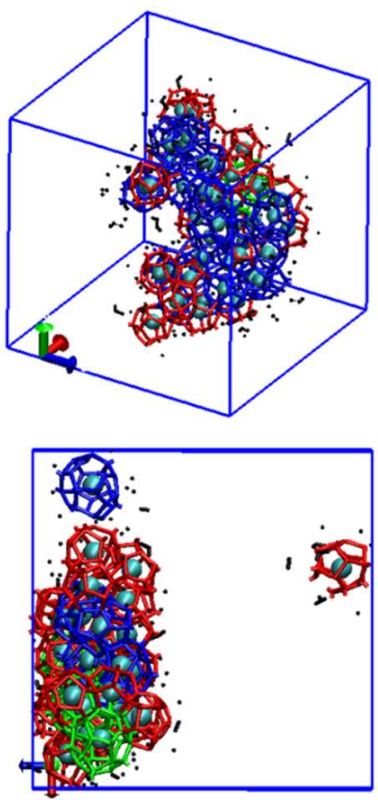
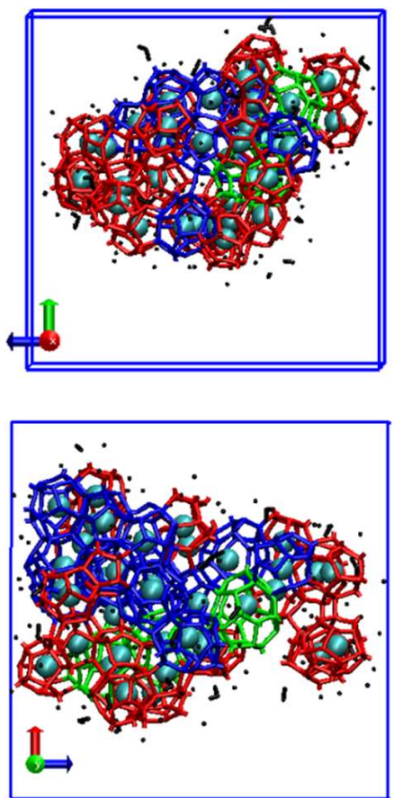

Figure 55- Characteristic configurations of methane clathrates in the presence of 0.04 mole fraction of methanol at $270 \mathrm{~K}$. In these panels, methane molecules inside cages are shown using a van der Waals representation in cyan whereas $5^{12}, 5^{12} 6^{2}$, and $5^{12} 6^{4}$ cages are represented in red, blue, and green, respectively. Methane and methanol molecules within $0.5 \mathrm{~nm}$ from cages are shown in licorice representation in black. Two $5^{12} 6^{2}$ cages in which methanol is the guest molecule are highlighted.

[1] Marcus G Martin and J Ilja Siepmann. Transferable potentials for phase equilibria. 1. united- atom description of n-alkanes. The Journal of Physical Chemistry B, 102:2569-2577, 1998.

[2] Monica E van Leeuwen and Berend Smit. Molecular simulation of the vapor-liquid coexistence curve of methanol. The Journal of Physical Chemistry, 99:1831-1833, 1995. 